\title{
Effect of Archimedes Screw Turbine Shaft Inclination on Output Power
}

\author{
Author: Khairul Muzaka ${ }^{1 *}$, Dian Ridlo Pamuji ${ }^{2}$, Mohammad \\ Abdul Wahid ${ }^{2}$, Syamsul Hadi ${ }^{3}$ and Jarot Dwi Prasetyo ${ }^{4,5}$
}

\begin{abstract}
Affiliation: Department of Mechanical Engineering, Ship Manufacture Engineering Study Program, Politeknik Negeri Banyuwangi, Indonesia ${ }^{1}$; Department of Mechanical Engineering, Mechanical Engineering Study Program; Politeknik Negeri Banyuwangi, Indonesia ${ }^{2}$; Department of Mechanical Engineering, Manufacturing Technology Engineering Study Program, Politeknik Negeri Malang, Indonesia ${ }^{3}$; Faculty of science and technology, computer science study Program, Universitas Ibrahimy, Indonesia ${ }^{4}$; PT. Bilzatama Inovasi Teknologi, Surabaya, Indonesia ${ }^{5}$
\end{abstract}

E-mail: zaka@poliwangi.ac.id ${ }^{1}$; ridlodian@poliwangi.ac.id²; abdul_wahid@poliwangi.ac.id ${ }^{2}$; syamsul.hadi@polinema.ac.id ${ }^{3}$; Jarot@binotech.co.id ${ }^{4,5}$

DOI: 10.26821/IJSHRE.9.3.2021.9314

\begin{abstract}
Rivers have enormous potential as a source of renewable energy. This potential is very abundant because there are so many rivers and irrigation canals that have a fairly large discharge. However, this irrigation channel has a low height, so it is necessary to select the suitable type of turbine if it is built for power generation. Archimedes screw turbine is the right choice for this condition, there are even several studies that exploit horizontal flow by using this Archimedes screw turbine to generate electricity. So that, this type of turbine is very suitable for power plant applications in Indonesia, where there are many low-altitude irrigation channels. There are several parameters that affect the electrical energy output produced by this screw turbine, among others; the outer and inner radius of the blade, the number of blades, the pitch, the amount of water flow, and also the angle of inclination of the screw turbine shaft. The purpose of this research is to find the appropriate angle parameters so as to produce maximum outputs. The variation of inclination angle which applied in this experiment are $30^{\circ}, 60^{\circ}$ and $90^{\circ}$. The inclination angle of the shaft that produces the greatest outputs from the research results is $60^{\circ}$ with the outputs of power $=38.7$ watts, voltage $=8.78 \mathrm{~V}$, electric current $=4.41 \mathrm{~A}$, and screw rotation $=210 \mathrm{rpm}$.
\end{abstract}

Keywords: Archimedes, Screw Turbine, Power, Inclination.

\section{INTRODUCTION}

Energy plays an important role in life, both for household needs and industrial needs. The energy generally used in life is electrical energy. Most of the electricity obtained by converting fossil fuels such as coal, which are in limited availability and continue running out every year[1]. The conversion of fossil fuels to electricity has a negative impact on the environment, this is because the conversion process produces greenhouse gases such as carbon dioxide, nitrogen dioxide, sulfur dioxide which cause global warming, and deteriorates the air quality, especially in big cities with many industries. Therefore, it is necessary to switch to renewable energy which is environmentally friendly and has unlimited availability. One of the renewable energy sources is river. There are many rivers in Indonesia, but they have a low altitude, so if they are used for power generation, it is necessary to find a turbine that suits these conditions. Apart from paying attention to water level conditions, ecological factors also need to be considered, so that fish life is not disturbed by the power plant. One type of turbine meeting these criteria is the Archimedes turbine screw, which is a turbine that can work at a low head[2, 3] with high efficiency[4] and safe for fish life [5]because it can be passed through by the fish while the turbine is running. The screw turbine with a compact design is very suitable for remote areas $[6,7]$ that need generators are easy to transport.

Several studies have been carried out related to the development of this Archimedes screw turbine. Using the Computational Fluid Dynamics study (CFD) Omar et al. 
Volume 9 Issue 3 March 2021

combine the number of blades and the tilt angle of the axle to get the optimal parameters[8]. This was also done by Muhammad et al. with the help of CFD software learn the effect of blade number on performance and pressure of Archimedes screw turbine[2]. Alkist et al. investigated the zero head horizontal Archimedes screw turbine theoretical performance prediction base on various linear actuator disk performance and S1/s2 algorithms[9]. Variation of screw angle range have been studied by Kamal et al. which increased efficiency up to $90 \%$ [10]. The same thing was done by Tineke et al. who conducted variation of shaft slope to study its effect on 3 bladed Archimedes screw turbine rotation[4]. Those study have shown many advantages of Archimedes screw turbine which require further study.

\section{MATERIALS AND METHODS}

The turbine screw used in this study has components made of several different types of materials, for turbine blades, the body and construction are made of PLA + material which is formed or made using a $3 \mathrm{D}$ printer, then the construction is reinforcement steel, the shaft and bearings are made of stainless steel. The 3D design of the Archimedes Screw turbine can be seen in Figure 1.
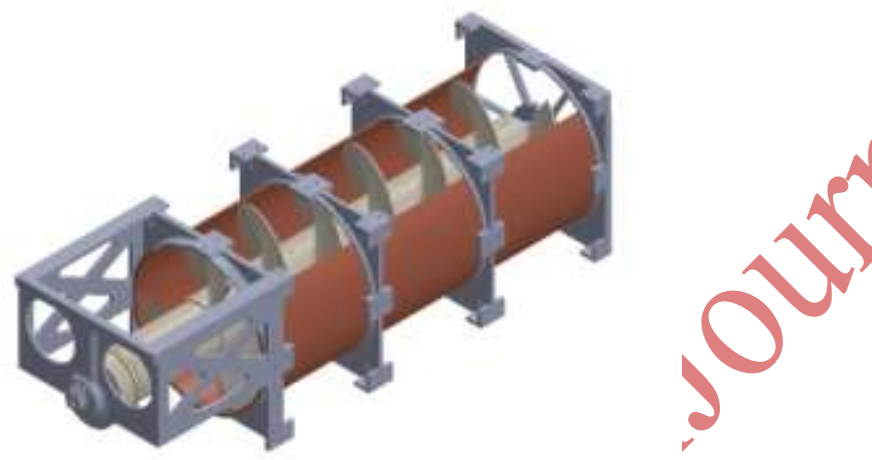

Figure 1 Screw 3D design.

In this experiment, the Archimedes screw turbine is installed in a construction made on the irrigation canal, so that it fits with the size of the screw turbine body. The angle of the screw turbine shaft can be adjusted according to the desired tilt angle. The setting of the turbine screw tilt can be seen in Figure 2

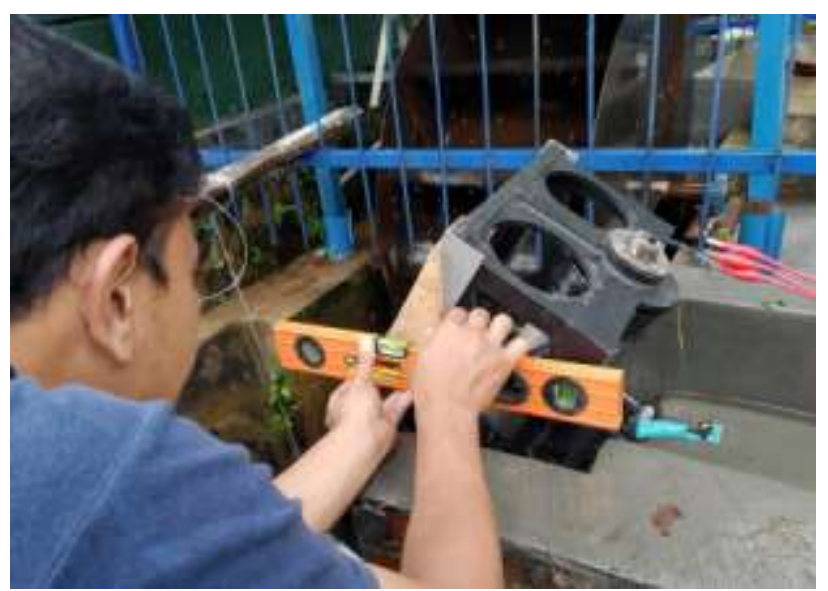

\section{Figure 2 Inclination setting.}

To find out the electrical output from the turbine, the electric generator in the turbine is connected to the current, voltage resistance, watt meter. Load setting is done by connecting the generator to the adjustable load. For all experiments the load was set at 2 ohms. The equipment of A, V, R, W meters can be seen in Figure 3, while for the schematic diagram of the working principle of these tools can be seen in Figure 4.

The research method in data collection begins with opening the water gates so that the water flows and pushing the turbine screw blades and then the kinetic energy of the water is converted into mechanical energy in the form of a screw turbine shaft rotation. Afterward, the mechanical energy is converted into electrical energy in the generator, the output of the electrical energy that comes out of the generator is measured in the form of electric current $(\mathrm{A})$, voltage $(\mathrm{V})$, power (Watt) with the measuring instrument in Figure 3, with all settings for the initial load is 2 ohms at adjustable load. The turbine screw shaft rotation is measured using a tachometer. All experimental parameters, both fixed and changing, such as the angle of inclination of turbine screw shaft, refer to Table 1.

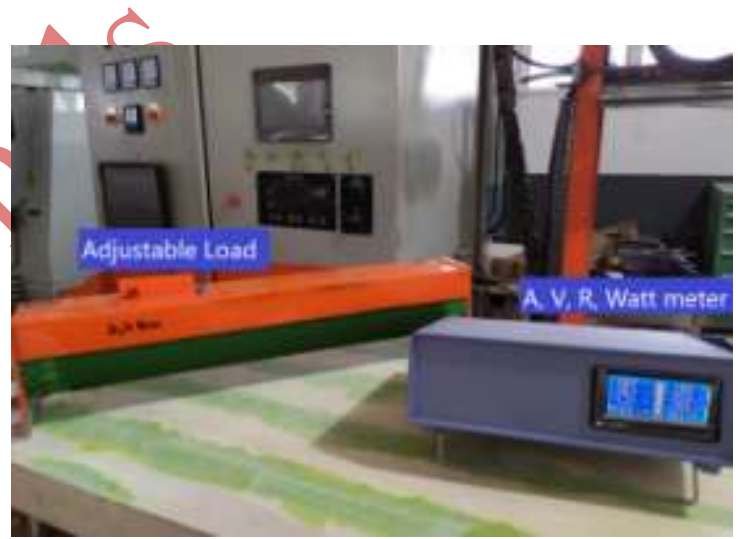

Figure 3 Electricity meter and Adjustable load.

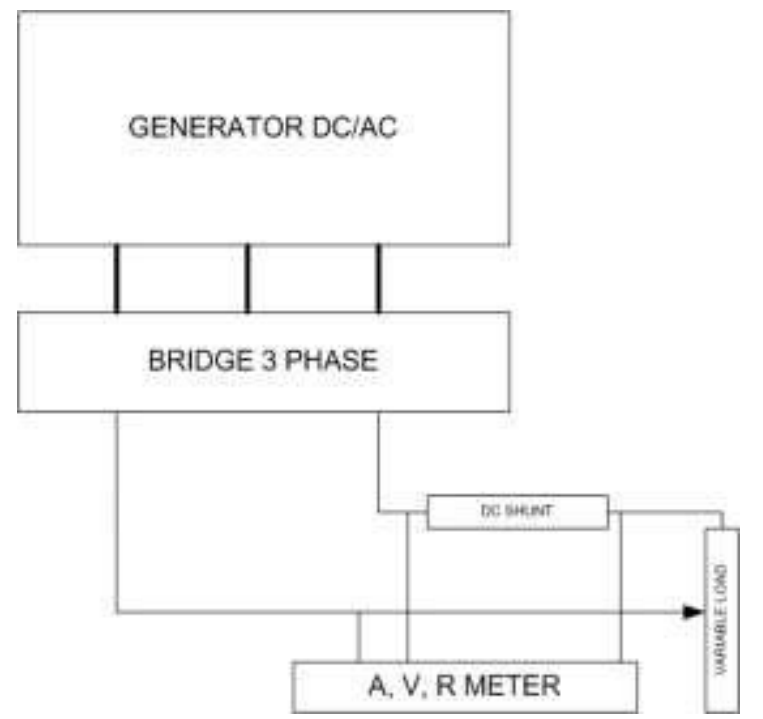

Figure 4. Schematic diagram of variable load and current, voltage resistance, watt meter 
Volume 9 Issue 3 March 2021

\section{Table 1. Screw turbine parameters}

\begin{tabular}{lcc}
\hline \multicolumn{1}{c}{ Parameter } & Variable & Value \\
\hline Inclination & $\alpha$ & $30^{0}, 60^{0}, 90^{0}$ \\
Outer radius & Ro & $156 \mathrm{~mm}$ \\
Inner radius & $\mathrm{Ri}$ & $61 \mathrm{~mm}$ \\
Pitch & $\mathrm{P}$ & $400 \mathrm{~mm}$ \\
Screw Length & $\mathrm{L}$ & $800 \mathrm{~mm}$ \\
Number of Blade & $\mathrm{N}$ & 3 \\
Flow rate & $\mathrm{Q}$ & $0,026 \mathrm{~m}^{3} / \mathrm{s}$ \\
Resistant & $\mathrm{R}$ & $2 \Omega$ \\
\hline
\end{tabular}

\section{RESULT AND DISCUSSION}

The results of the screw turbine experiment can be seen in the following table and figures. Table 2 shows where the initial fixed parameters such as pitch, screw length and load, as well as changing parameters such as shaft tilt angle. The table also shows the output of the experiment which includes voltage, electric current, power and turbine shaft rotation.

\section{Table 2. Output data}

Pitch Length Inclination Voltage Current Resistant Rotation Power

\begin{tabular}{cccccccc}
$(\mathrm{mm})$ & $(\mathrm{mm})$ & $(\mathrm{Deg})$ & $\mathrm{V}$ & $\mathrm{A}$ & $\Omega$ & $(\mathrm{rpm})$ & $(\mathrm{Watt})$ \\
\hline 450 & 800 & 30 & 8,19 & 4,03 & 2 & 195 & 33 \\
450 & 800 & 60 & 8,78 & 4,41 & 2 & 210 & 38,7 \\
450 & 800 & 90 & 6,98 & 3,43 & 2 & 165 & 23,9 \\
\hline
\end{tabular}

In Figure 5 shows the value of the voltage is about $8 \mathrm{v}$ less at the angle of inclination of $30^{\circ}$ on the screw turbine shaft. Then the graph shows that the value of the voltage increases to approach the value of $9 \mathrm{v}$ at the angle of inclination of the turbine screw shaft $60^{\circ}$, continues to decrease in the range of $7 \mathrm{v}$ at the tilt angle $90^{\circ}$, then it can be concluded by considering the graph, that the largest voltage value, which is about $9 \mathrm{v}$, is obtained by the tilt of the shaft screw at $60^{\circ}$.

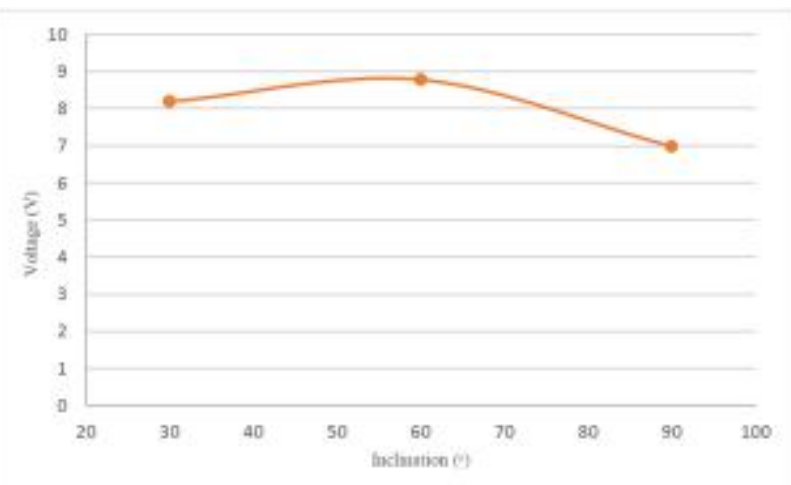

Figure 5 Output voltage of screw turbine with 3 different inclinations.

In Figure 6, where the turbine screw shaft tilt angle of $30^{\circ}$ produces an electric current of about $4 \mathrm{~A}$ which continues with a slight increase in the angle of the turbine screw shaft $60^{\circ}$ with a value approaching $4.5 \mathrm{~A}$. Then, the graph shows a decrease with the value of the electric current below $3.5 \mathrm{~A}$ at shaft slope of $90^{\circ}$. It can be concluded from Figure 6 that the largest value of electric current is obtained with the axle angle of the turbine screw $60^{\circ}$.

The rotation of the turbine screw can be seen in Figure 7, at the angle of the turbine screw axle $30^{\circ}$, the rotation is close to $200 \mathrm{rpm}$ which then increases up to about 210 rpm at the axle slope loss of $60^{\circ}$, then decreases the rotation slightly above $150 \mathrm{rpm}$ at the turbine screw axle angle of $90^{\circ}$. From this graph it can be concluded that the $60^{\circ}$ angle produces the highest rotation from the other tilt angles, which is around $210 \mathrm{rpm}$.

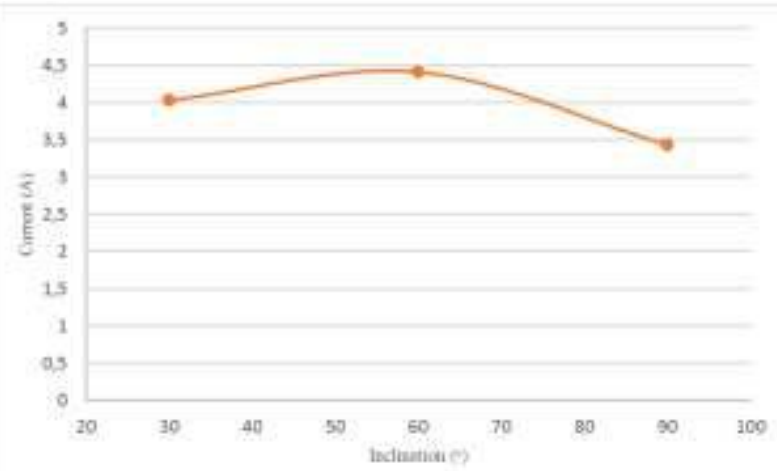

Figure 6 Output electricity current of screw turbine with 3 different inclinations

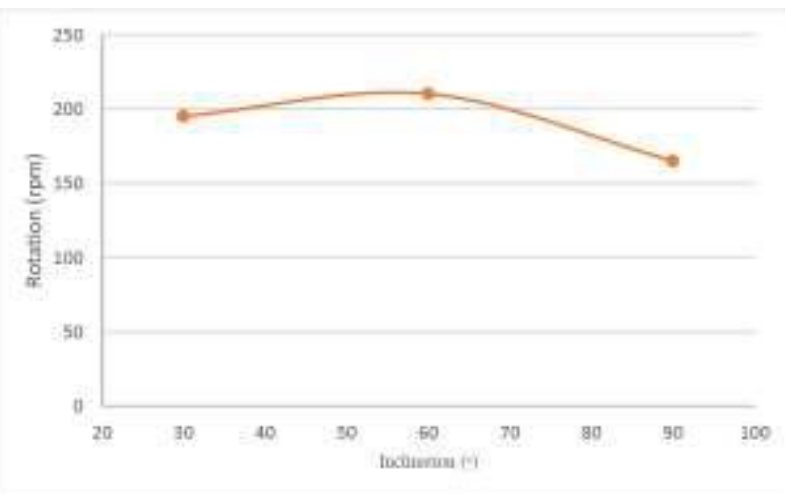

Figure 7 Output rotation of screw turbine with 3 different inclinations

The output power of the turbine screw with 3 variations of the axle tilt angle can be seen in Figure 8. The screw turbine shaft tilt angle at $30^{\circ}$ the power is about 33 watts, which then increases to close to 40 watts at the shaft tilt angle of the screw turbine $60^{\circ}$, and then drops just below 25 watts at the shaft tilt angle of $90^{\circ}$. Then it can be sure, at the axle tilt angle of $60^{\circ}$ produces the greatest power when compared to the tilt angle of the shaft of the other screw turbines. 
Volume 9 Issue 3 March 2021

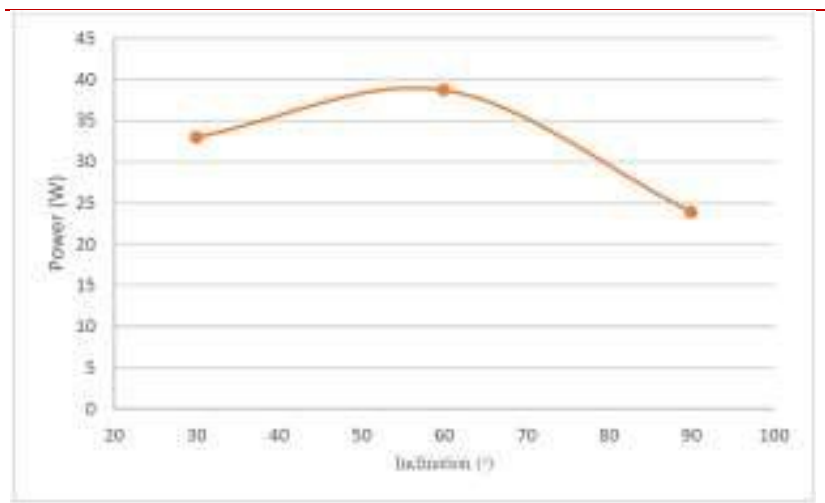

Figure 8 Output power of screw turbine with 3 different inclinations

\section{CONCLUSION}

Archimedes Screw turbine from design, manufacturing and experiment can be drawn the following conclusions:

1. Specifications of the Archimedes screw turbine are as follows; The turbine has 3 blades with dimensions of length $(\mathrm{L})=800 \mathrm{~mm}$, inner radius $(\mathrm{Ri})=61 \mathrm{~mm}$, outer radius $(\mathrm{Ro})=156 \mathrm{~mm}$ and pitch $(\mathrm{P})=400 \mathrm{~mm}$.

2. The independent parameters in the experiment are the load $(\mathrm{R})=2 \mathrm{ohms}$ which is set on the adjustable load and water debit $(\mathrm{Q})=0.026 \mathrm{~m} 3 / \mathrm{s}$. while the parameters that change are the angle of the Archimedes screw turbine shaft, namely: $30^{\circ}, 60^{\circ}, 90^{\circ}$.

3. From the experiment results, the optimal outputs are obtained consistently at the angle of the turbine screw shaft $60^{\circ}$, among others: Voltage $=8.78 \mathrm{~V}$, Electric Current $=4.41 \mathrm{~A}$, Rotation $=210 \mathrm{rpm}$ and Power = 38.7 watts.

\section{ACKNOWLEDGMENTS}

Our thankfulness goes to Politeknik Negeri Banyuwangi which have provided funding for Archimedes screw turbine research project.

\section{REFERENCES}

[1]. Muhammad Ilham Maulana, A.S., Rizki Kurniawan, Experimental Study on the Effect of Flow rate on the Performance of Two-Blade Archimedes Screw Turbine. Journal of Advanced Research in Fluid Mechanics and Thermal Sciences 2019. 61(1): p. 1019.
[2]. Muhammad Ilham Maulana, A.S., Muhammad Nawawi, Blade Number Impact On Pressure And Performance Of Archimedes Screw Turbine Using $C F D$, in The 3rd International Conference on Industrial, Mechanical, Electrical, and Chemical Engineering. 2018, AIP Publishing. p. 7.

[3]. Irwansyah, M.I.M., Ahmad Syuhada, Design and Performance of Archimedes Single Screw Turbine as Micro Hydro Power Plant with Flow Rate Debit Variations (Case Study in Air Dingin, Samadua South Aceh) Jurnal Inovasi Teknologi dan Rekayasa 2019. 4: p. 13-22.

[4]. Tineke Saroinsong, R.S., Slamet Wahyudi, Mega N. Sasongko, Performance of Three-Bladed Archimedes Screw Turbine. ARPN Journal of Engineering and Applied Sciences 2016. 11: p. 9491-9495.

[5]. Adam T. Piper, P.J.R., Rosalind M. Wright, Paul S. Kemp, Corrigendum to "The impact of an Archimedes screw hydropower turbine on fish migration in a lowland river" Ecological Engineering, 2019. 127: p. 11.

[6]. Fiardi, E., Preliminary Design of Archimedean Screw Turbine Prototype for Remote Area Power Supply Journal of Ocean, Mechanical and Aerospace 2014. 5: p. 30-33.

[7]. Pallav Gogoi, M.H., Subrendu Purkayastha, Khemraj Newar and Potential of Archimedes Screw Turbine in Rural India Electrification: A Review Journal of Electrical and Electronics Engineering (AJEEE), 2018. 2(1): p. 30-35.

[8]. Omar Sulaiman Abdullah, A.H.K., Wissam Hashim Khalil Numerical and Experimental Modelling of Small Hydropower Turbine. Journal of Advanced Research in Fluid Mechanics and Thermal Sciences 2021. 80(1): p. 112-127.

[9]. Alkistis Stergiopoulou, V.S., Efrossini Kalkani, Experimental and theoretical research of zero head innovative horizontal axis archimedean screw turbines International Journal of Energy And Environment, 2015. 6(5): p. 471-478.

[10]. Kamal Kashyap, R.T., Sunil Kumar, Rajkumar, Identification of Archimedes Screw Turbine for Efficient Conversion of Traditional Water Mills (Gharats) into Micro Hydro-power Stations in Western Himalayan Regions of India: An Experimental Analysis International Journal Of Renewable Energy Research, 2020. 10: p. 14511463. 